\title{
Figures 1 and 2, and Why You Should Worry a Lot More About These Figures Than the One We Showed You in 2014
}
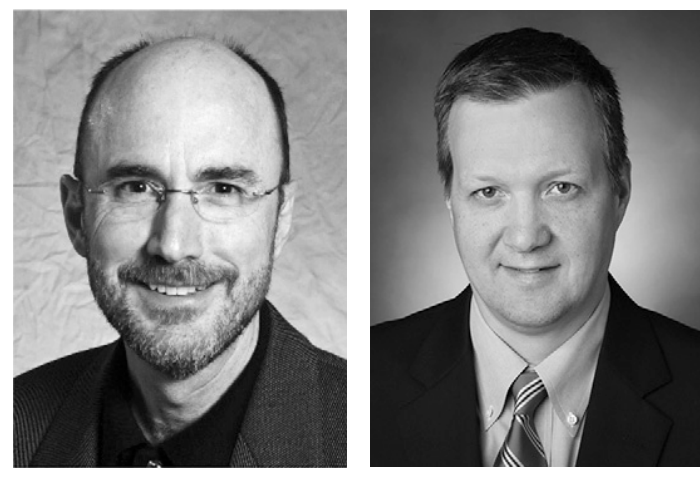

DOI: $10.3766 /$ jaaa.30.4.1

$\mathrm{F}$ ive years ago Gary Jacobson authored an editorial for this Journal about the shrinking number of Ph.D.s in the field of audiology (Jacobson, 2014). The title of the piece was "Figure 1 and why it should worry you (at least a little bit)." In that editorial it was suggested that a large number of Ph.D. level audiologists were nearing the retirement age of 65 years. In fact it was suggested that, over the next 10 years, our profession might lose as many as $40 \%$ of the total cohort of $\mathrm{Ph} . \mathrm{D}$. level, both basic and applied (i.e., translational), audiological researchers. We decided to "circle back" and re-assess the state of affairs. Unfortunately, the news continues to be bleak.

Figure 1 is a line plot of the current age distribution of audiologists holding Ph.D. degrees (Data courtesy of Rachael Sifuentes, AAA). These individuals received either a Ph.D. degree or both the Au.D. and Ph.D. degrees. The total was 578 Ph.D. audiologists. The age distribution of these individuals reveals a peak in the age distribution between 61 and 71 years of age. At the peak (most apparent at 66-70 years of age) there are $100+$ audiologists holding Ph.D. degrees. Unfortunately, between 36 and 55 years of age, the numbers of Ph.D.s has remained relatively flat at about $50 \mathrm{Ph}$.D.s. This suggests that as the "greying of audiology" progresses, we run the risk that a large proportion of our Ph.D. audiologists will be retiring. In this regard, Figure 2 shows the age distribution of the existing practicing Ph.D. audiologists for the years 2012, 2015, and 2018. It is easy to see that the $225 \mathrm{Ph} . \mathrm{D}$. audiologists in 2012 who were 51-60 years of age was reduced to $<150$ Ph.D. Ph.D. audiologists in 2018 representing a reduction of $75 \mathrm{Ph} . \mathrm{D}$. audiologists or $33 \%$ (Data courtesy of Sarah Slater, ASHA).
So what does this mean for our Profession? Well, if you are a young Ph.D., or if you are an aspiring Ph.D. student, who has a dream of being employed as a university professor in a department of communication disorders, there is a high likelihood you will attain that goal. It is clear that, unless academic programs close, there will be a tremendous need for teachers. However, in our opinion, these data carry a more ominous message. They suggest that there will be fewer than needed Ph.D. teachers and researchers who will be prepared to contribute to the science-base of our Profession. We fully realize that being a successful educator/researcher is more than being a gifted teacher. The choice to become a career scientist/educator carries with it the trap door associated with the constant pressure to be successful in competing for grant funding.

If we do reach a point where audiologists are not significant contributors to the science of our profession, where other professions assume the responsibilities for the discoveries, then, simply put, the game is over. It is time to "right the ship." We need to understand how, when, and why we drifted off-course and then also determine what might be remedies. It is essential that we supplement the cadre of doctoral practitioners with Ph.D. scientists who have the both the training and drive to move forward "Our Great and Noble Profession."

Gary P. Jacobson, Ph.D. Devin L. McCaslin, Ph.D. The Editors

\section{REFERENCE}

Jacobson GP. (2014) Figure 1 and why it should worry you (at least a little bit). J Am Acad Audiol 24(6):450-451. 


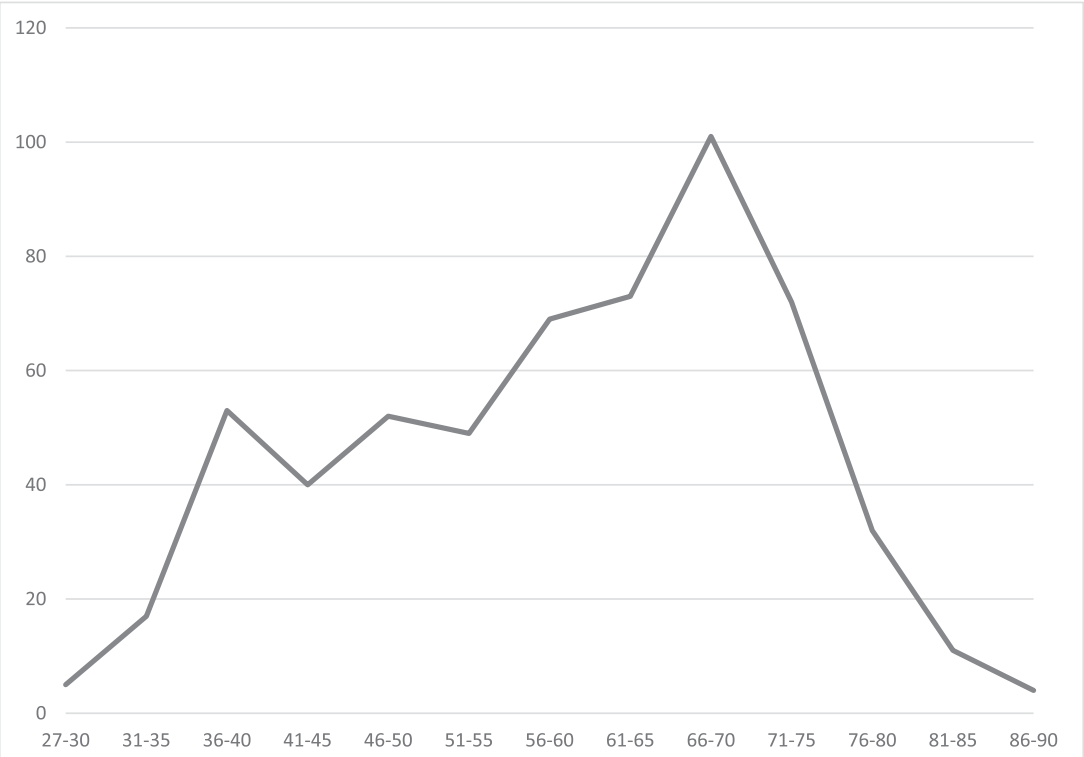

Figure 1. Current age distribution of audiologists holding the Ph.D. degree. The " $y$ " axis is the numbers of audiologists and the " $x$ " axis represents the age-ranges of the audiologists (Data courtesy of Rachael Sifuentes, M.A., AAA).

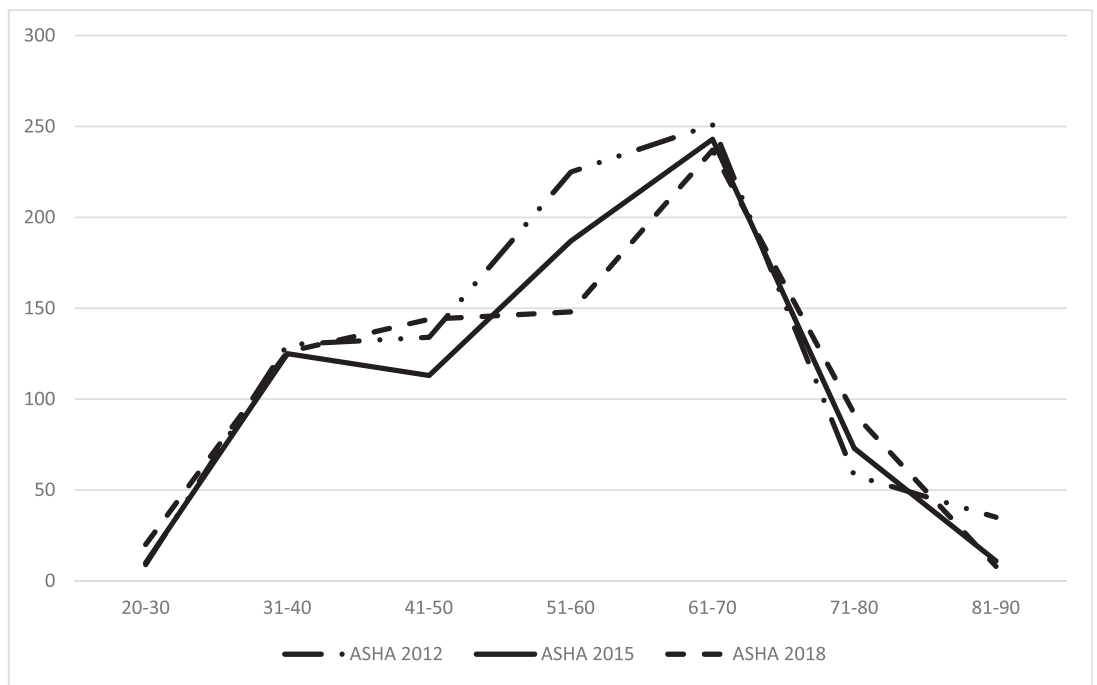

Figure 2. Age distribution of audiologists holding the Ph.D. in the years 2012, 2015, and 2018. The "y" axis is the number of audiologists and the "x" axis represents the age-ranges of the audiologists (Data courtesy of Sarah Slater, ASHA). 